\title{
Just in Time Teaching and Learning System in the Standard e-Classroom
}

\author{
Gabriel ZAMFIR \\ Department of Economic Informatics and Cybernetics, \\ The Bucharest University of Economic Studies, Romania \\ gabriel.zamfir@ie.ase.ro
}

E-society is a just in time learning system, based on versioning technologies. E-science is a similar system, too, but it is based on recursive educational processes and iterative implementations of technologies. E-education is by definition, and by default, a just in time learning system. E-society is a native environment for all forms of the traditional education: formal, non-formal and informal education. At the same time, e-society is a native environment for structured educational resources: electronic, digital and virtual resources. In this context, the standard e-classroom become the native environment in order to develop a just in time teaching and learning system. This article presents the conceptual framework as a knowledge one, for such an approach, based on the meta language and the object language, as a twofold research paradigm, and details the theoretical framework as a comprehension one, and the analytical framework, as an application for a solution, including a case study.

Keywords: Scientific Researches in e-Education, Digital Articles, Assisted Instruction, Teacher Assisted Learning, Standard Assisted Instruction Applications, Standard Assisted Individual Studies

\section{1} Introduction

Information Technology as a scientific research domain changed the vision of the users between theory and practice and become escience. At the same time, Information Technology developed business as e-business and offered the context to extend education as eeducation. Theory become a recursive process for theoretical knowledge structuring and refining and practice become an iterative process for educational implementations of knowledge as new versions of the applications. E-education should become the engine of the $e$-society as soon as e-business reflects versions of technologies and e-education has to integrate recursive processes in order to prepare the professionals.

E-society represents a threshold concept when we structure the educational resources of the environment generated by the $e$-science (considered an aggregate concept, including $e$-education). Three categories are already basis concepts, accessible for a standard user analyse. The first one, the electronic resources represent the traditional resources, projected in the new context, for example, all printed books, scanned, stored, and available in elec- tronic format. The second one, the digital resources, they are new, for example, the digital services, designed in order to purchase a ticket for a flight. The third one, the virtual resources, reflects an augmented reality, for example, a visit in a virtual museum. This approach dedicated to the concept $e$-society explains how the three forms of the traditional education: formal, non-formal, and informal education, all of them growths in the same electronic new context.

As soon as this analyse highlights learning, as a basic activity of the human development, it is useful to mention here the three paradigms of learning in e-society, as they describe the concept in [1]: a lexical paradigm, a terminological paradigm, and a conceptual paradigm, three levels of understanding of the same process using different cognitive infrastructures, different technological infrastructure, and different conceptual infrastructure. The explanation of such a phenomenon is because the character of human reasoning which it is different during various stages of the development of an individual human cognitive system.

For example, in [2], based on reviews of pio- 
neering work within smart learning, smart education, and smart learning environments, the authors highlight two models, a cognitive smart learning model, and a smartness level model. These models are evaluated against current standardization challenges in the field of learning, education and training to form the basis for a development platform for new standards in this area. Another example is [3]; in this paper, smart learning environments are defined as physical environments that are enriched with digital, context-aware, and adaptive devices, to promote better and faster learning. In order to identify the requirements for 'better and faster learning', the idea of $\mathrm{Hu}$ man Learning Interfaces is presented, i.e. the set of learning related interaction mechanisms that humans expose to the outside world that can be used to control, stimulate and facilitate their learning processes. Papers highlighting standards for smart education, smart learning environments, and even smart learning, propose descriptive metaphors, and all of these phrases refer to the lexical paradigm. Onestep to an explanatory metaphor is smart education framework. In [4] the authors describe the three essential elements in a technologyfacilitated smart education environment, which are teaching presence, technological presence, and learner presence. Both the instructor and students share the teaching presence. It describes the teaching role in a smart education system as instructional design, facilitation and direct instruction, and technological support. The learner presence consists of learners' competency to being autonomous and collaborative learners as well as efficient users of technologies. The technological presence concerns to what extent technologies can create connectivity, provide ubiquitous access to learning resources, and adapt to personal needs. The technological presence provides a foundation for learning to occur.

Another explanatory metaphor is developed by [5] referring to 'blended learning ecosystem' using a conceptual learning paradigm of working professionals. They define the learning needs of this learner audience, which are context-centric, action-oriented, participation-based, and skills-focused.
Such an approach based on an explanatory metaphor referring a terminological paradigm or to a conceptual paradigm, it is recommended when we work for cognitive development of the learner, which it tends to complete as a cognitive autonomous system.

\section{Knowledge Framework as a Conceptual one}

Analysing scientific researchers as learners, according to previous educational researches, [6] and [7] define the article as the basic result of the scientific research activities, structure the main papers types and present a refined working model developed as a paradigm in the process of elaborating articles. Analysing scientific research as a self-educational activity, [1] highlights the article as an object learning so for the owner, and for the community with the professional interests in the same field's area.

Information Technology, as a scientific research domain, transformed the knowledge framework in a conceptual one, and one referential moment was when Intel's first microcomputer on a chip, the 4004, was conceived by Marcian Edward "Ted" Hoff and Stan Mazor, in 1971, being a more general purpose, replacing logic circuits with microprogramming. This solution promoted the idea of including a computer inside a computer, the second one being updated with a new technology [8]. Understanding programming as a native environment of the scientific domain in Information Technology, we include the meta language and the object language, as a twofold research paradigm, in any approach. So, passing from conceptual framework to a theoretical framework, we use working terms as a meta language, while, developing an analytical framework, we use the scientific field's terms as an object language. A pattern application should be used in defining a case study. It is important to distinguish between recursive educational processes and iterative implementations of technologies, which could reflect different levels of professionals (certified or not, known or unknown) or different versions of technologies (standardized or not, registered or not). Including such an approach 
for analysing scientific researchers as learn-

1. ers, an updated paradigm of the scientific research article in e-education it is shown in Fig.

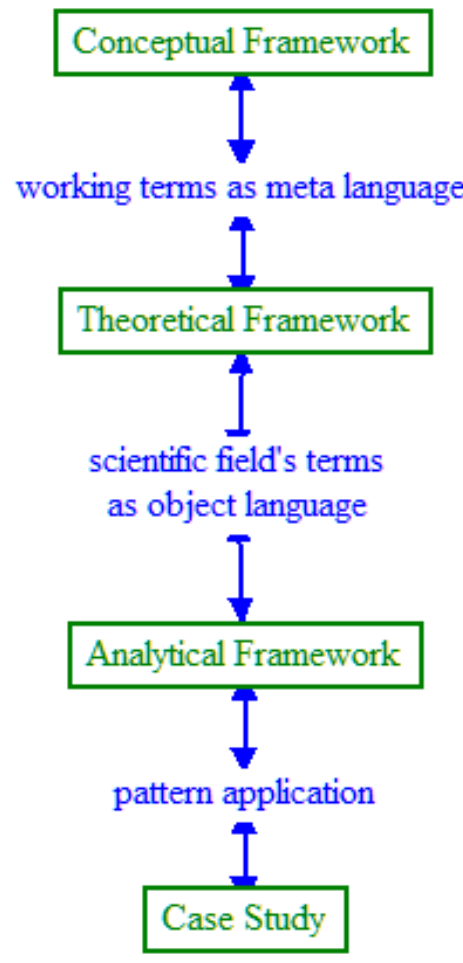

Fig. 1. A paradigm of the scientific research article in e-education

Matching the interests of the other researchers or students depends on the adequate informational granularity of the object learning. At the same time, e-science requires reconsidering the relationship between theory and practice and the paradigm of space and time, for learning. E-science transformed the article in electronic article (e-article), and as a pattern applied, object learning was developed, designed and implemented as e-object learning. According to the three categories of resources in e-society, the next stage for the traditional scientific article is the digital-article ( $d$-article), which it should integrate explicit functionalities.

In order to create paradigms and to use metaphors in a teaching-learning system, we define the meta-language as being a method and the object-language as being a technique. Scientific research is a methodological investigation of a scientific subject of a particular domain for adding to knowledge, as a theoretical approach, and confirmed in a case study, as a practical approach. The scientific progress integrates the equilibrium between methods (defined as theoretical approaches) and techniques (defined as practical approaches). In fact, we develop the methodological approach based on concepts map, presented in [1], which mentions the desktop-fieldwork paradigm, as a base of a threefold actions of a basic teaching and learning system: knowledge, comprehension and applications, in order to configure a user cognitive infrastructure. As a teacher, a user cognitive infrastructure presumes to know, to understand and to apply the meta-language, while, as a learner, the user cognitive infrastructure supposes to know, to understand and to apply the object language. The building blocks of an e-education framework implies two others infrastructures: the technological one and the conceptual one, as we observe in [9]. Defining such a teachinglearning system, it is mandatory to conclude that the features of all the infrastructures implied certify the characteristics of the learner's cognitive system resulted. 
These three infrastructures define the external factors, but very important are the internal factors of a learner's cognitive system. The internal factors of a learner's cognitive system could be structured in: primary competences (attention and patience, integrated in a selfdiscipline), secondary competences (motivation and objectives), and tertiary competences, based on computer literacy and explicit professional skills.

In [10], the authors explore new forms of teaching, learning, and assessment for an interactive world, to guide teachers and policy makers in productive innovation. This seventh report proposes ten innovations that are already in currency but have not yet had a profound influence on education. Making thinking visible is one of them and it fits with a view of learning as a constructive activity. Technology-enhanced assessment prompts students to show their working as they solve problems and receive automated feedback. Some systems also allow students to pose questions and discuss their progress with teachers and peers during a learning activity. Teachers can see how each student is progressing towards mastery of a topic and can identify where students are blocked or have misunderstood a topic. Decolonising learning: a curriculum provides a way of identifying the knowledge we value. It structures the ways in which we are taught to think and talk about the world. Place-based learning: Where learners are at a given time influences what they experience, their feelings, and their ways of thinking. These opportunities are limited if study always takes place in similar settings such as classrooms, lecture halls, or libraries. Place-based learning considers location to be a trigger for learning and an active part of how people learn. It is an approach that involves looking for learning opportunities within a local community and using the natural environment to inspire learners. It can support learning about a wide range of subjects, including Culture and History, Geography and Science. Mobile technologies are opening up new opportunities for place-based learning. They offer a sophisticated set of tools that can be used to support study outside the classroom. They also provide opportunities for adding virtual information to physical settings.

The main features of an e-education system are the global functionalities and the diversity of the users. The technological infrastructure presumes different levels of the information systems (home-based, institutional, metropolitan, national, regional, and global) while the conceptual infrastructure assumes study programmes based on curriculum, subjects, syllabuses and concepts map.

Therefore, the methodological approach based on concepts map in e-education shows the functional updates in Fig. 2, where the generic user stands for scientific researcher, teacher or student.

The central point of this new approach and the main feature of the e-education context is consisted of the desktop as a fieldwork paradigm; the phrase is a general one of another three already classical metaphors for the desktop: school desk, master desk, and desk or table. It is essential to differentiate these three metaphors, which are descriptive metaphors, comparing with the desktop as a fieldwork, which is an explanatory metaphor. One more example for a descriptive metaphor is the typewriter assuming for a word processor, which highlights a limited comprehension of a new concept according to a descriptive metaphor, and not to an explanatory one, like the word processor - an instruction environment for processing a scientific research project.

The desktop as a fieldwork paradigm represents the key resource of the methodological approach based on Information Technology as a native scientific research environment and this explanatory metaphor presumes a threefold meta-instruction activity for a generic user, in a just in time teaching and learning system, in the standard e-Classroom. The student-user interacts with adequate content, because of systematically refined activities of the teacher-user, in a specific technological infrastructure, acting (knowing, understanding, and applying) in a cognitive infrastructure developed as an extension of his cognitive system. The scientific researcher-user discovers new methods and techniques, available as 
knowledge and applications, in order to develop the methodological approach, of a just in time teaching and learning system, in e-education, and in particularly, in a standard $e$ Classroom. The new content transforms the user, from a student-user stage in a teacheruser stage or a scientific-researcher stage, as circular references, depending on context, and new technologies transform the methodological approach according to the new ontologies.

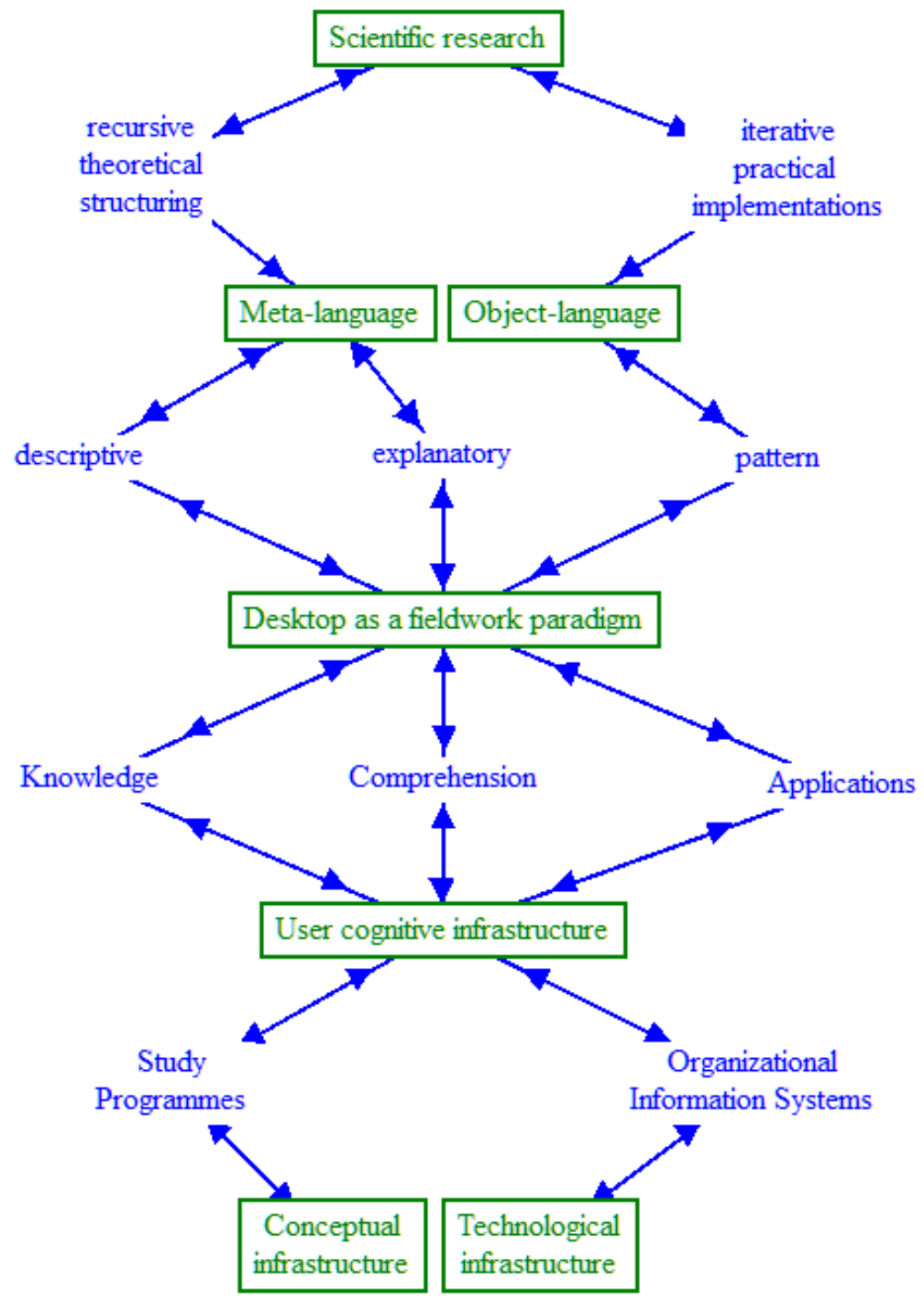

Fig. 2. Methodological approach based on Information Technology as a native research environment

Such kind of approach focuses on the user's cognitive infrastructure, defined as the environment of the cognitive development of the student, in order to create a cognitive system for the user. Desktop as a fieldwork paradigm is the base for metacognitive development, being a construct, which presumes, at the same time, a meta-language, and an object language, a method for the teacher and a technique for the learner.

\section{Comprehension Framework as a Theo- retical one}

Using the concept of $e$-society as an explanatory metaphor educational laboratory, we understand that e-education includes the traditional education, and it is evolving based on technological infrastructure, conceptual infrastructure, and very important, the cognitive infrastructure, including here the instructional escience applications, developed as cognitive 
extensions. Based on the building blocks of the scientific research activities (ontology, epistemology, methodology, and methods) and on the interrelationships between the building blocks of assisted instruction in e-ed- ucation, developed in [11], we create a theoretical framework, dedicated as a base for initiating an operational assisted instruction system in e-education; see the image presented in Fig. 3.

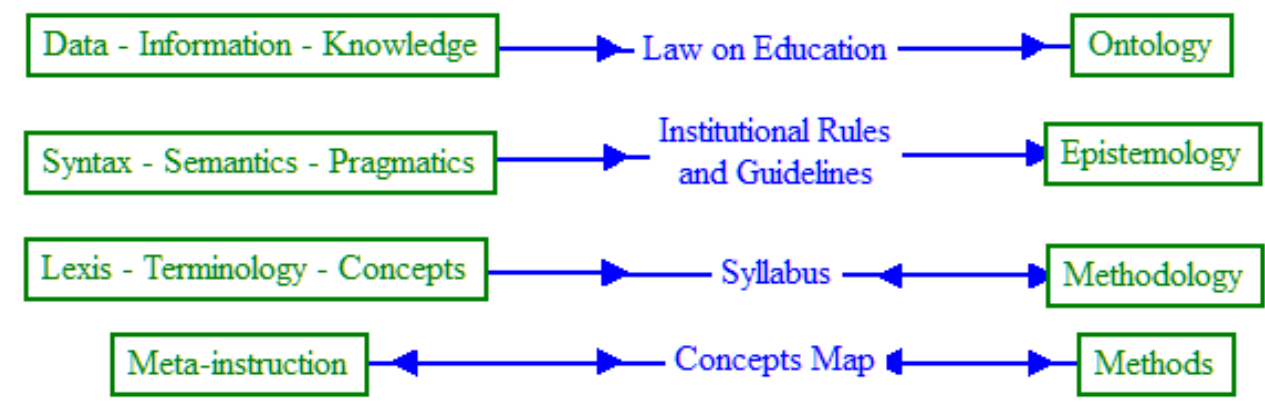

Fig. 3. Comprehension Framework based on assisted instruction in e-education

In our educational laboratory, we can find guidelines developed to assist countries wishing to assess the compatibility of their national education laws and policies with international standard-setting instruments on the right to education [12]. In Romania, the traditional education system depends on Law on Education. Law on Education [13] consists of 365 articles, structured in titles, chapters, and sections; there were operated 88 updates during eight years, 13 of them in the first eight months of 2019. The third article consists of 21 principles. The law regulates a complex and dynamic context, in order to shape the human personality.

Each higher education institution elaborates rules and guidelines for didactic activity, based on Law on Education. Each discipline has a syllabus, consisting of estimated total time, prerequisites, conditions, acquired specific competences, objectives, and content, mentioning teaching work methods, and recommendations for students. The final section is about assessment: criteria, methods and the final grade.

Integrating the traditional class, as course and seminar, in a laboratory activity, we develop the e-education system, as an extension of the traditional education system, in order to assimilate the new concepts in the Law on Education.

Using the concept $e$-society defined as a society of the systems, [9] highlights the main teaching-learning systems in e-education, which depend on time and space: T-Class (different places, the same time), $P$-Class (different time, the same place), e-Class or virtualClassroom (different places and different time), and e-Classroom (the extension of the traditional classroom, the same time, and the same place).

The e-Classroom, which integrates assisted instruction, consisting of computer-assisted instruction and teacher assisted learning, presumes principles, as any other human activity. The same principles reveal the foundations for of any software application or service of an eeducation system.

In e-education, individualized educational activities represents the first principle, and this is the basis characteristic of a standard $e$ Classroom: each student uses his own personal computer. The second principle descends from the first one: personalized learning integrates the student-own-pace concept. Cognitive interactivity defines the functionalities of a learning system in e-education. Based on the triple-vision of the personal computer as tool, tutor, and tutee, the third principle depends on the adequate information granularity of the electronic, digital, or virtual content. This third principle of the e-education progresses in a concept map approach and depends on standard assisted instruction applications and standard assisted individual studies. Two more principles use technology developments as a meta-discipline: while it integrates interdisciplinary approaches because of the 
diversity as forms of knowing and transdisciplinary approaches because of the diversity as forms of knowledge. This group of five principles presented in [14] has to be transformed in a system improved according to a cybernetic approach. Developing computer literacy as a meta-discipline consists the basis of the sixth principle of the e-education: self-control of learning through self-assessment. This sixth principle become the engine of the process of completing the user's autonomous cognitive system, independently of the stage of the learner: the student, the teacher or the scientific-researcher.

\section{Application Framework as an Analytical one}

Developing computer literacy as a meta-discipline consists the foundation for creating, using and versioning educational software, too. 32 years ago [15], in the ninth chapter, Problems and promises, in the section The Future, at page 284, it contains the authors' conclusion: "As a result of the expanded capabilities of technology, teachers will have different functions than they do today. They will spend more time attending to the needs of individual students and less time worrying about class norms. They will be relieved of tedious nonteaching task such a maintaining attendance and performance records; and they will become the skilled managers of complex instructional systems that bear little resemblance to today's classrooms." The conclusion had to be correlated with the need to train teachers to use the technology making computer literacy mandatory for every graduating teacher. This point of view is understandable correlated with the fact that in 1958, the United States was the first country to study computer-assisted instruction and in 1963, there was a computer assisted instruction system developed for university education, which surfed the worldwide study of this topic [16]. The same author mentions that there is still a wide gap in this field due to the poor universality of relevant software, which has restricted its widespread application in the education industry as well as the disengagement between the content of curses and the reality since these curriculums were designed merely based on cognitivism and behaviourism. In 2001, in [17] the concept of a large multilevel class could be found, and the author was detailing qualitative aspects of this subject (language acquisition ability, age, motivation, intelligence, self-discipline, literacy, skills, attitude, and interest), but also, quantitative aspects (in China they thought groups of sixty students or more in classes, in Pakistan the groups were over one hundred students, in the language institute where she thought for many years, twenty students was considered a large class, but also highlighted another author, $\mathrm{H}$. Douglas Brown in his Teaching by Principles, Prentice Hall Regents, 1994, who wrote about the possibilities of classes that have 600 students (mentioned as an unusual number). We found in the second edition of $\mathrm{H}$. Douglas Brown's book a clarification (the latest edition being published in 2015, as the fourth). In [18], in Chapter 13, Classroom Management, in the section Teaching Under Adverse Circumstances, the author mentioned: "I was once asked by a student in a teacher education course about how to deal with large classes. I began to list the kinds of adjustments he could make with classes of fifty or seventy-five students, when he said he meant really large classes: somewhere in the neighbourhood of 600 students! As I caught my breath, my only response was to ask him how he would teach 600 people to swim in one swimming pool without displacing all the water in the pool!". The previous researches focused on $e$-Classroom and on the main components of a teaching-learning system in e-education, revealed two phrases already classics: Computer Assisted Instruction and Teacher Assisted Learning. They are useful components in the theoretical framework section presented in [19]. This approach reflects e-Classroom as an extension of the traditional classroom, because face-to-face teaching, learning, assessing and self-assessing are included; at the same time, it confirms that the prefix " $\mathrm{e}$ " from electronic could be applied to an information system, but not to an activity based on human thinking. 
New services, presumed by an organizational information system are included, such as intranet-personalized services, intranet customizable services, web customizable services and web personalized services. The web services create a connection with the e-classroom from home, for example, as an extension for homework. All the activities, projects, and instructional applications proposed in e-classroom are available and workable at home.

Computer Assisted Instruction presumes two types of components: standard assisted individual studies and standard assisted instruction applications. They are labelled as standard as soon as they are permanent updated, based on the track and on the feedback, mechanisms integrated by the Teacher Assisted Learning presence. In order to support these mechanisms, teacher observes two compo- nents of the learner's cognitive system: personalized learning when threshold concepts are revealed and tacit knowledge when troublesome knowledge encountered. Assisted instruction applications review the basic concepts, the aggregate concepts, and the threshold concepts of a fieldwork, while assisted individual studies review methods, methodologies and theories of the same fieldwork. First class of techniques focus on knowledge, comprehension and application, while the second class focus on analysis, synthesis and evaluation, as they are the six levels of the Bloom's taxonomy, used in the paradigm of meta-instruction. Therefore, the standard functionalities for an assisted instruction system in $e$ Classroom, as one of the fourth teachinglearning standard systems in e-education, reflects the new context, in the image presented in Fig. 4.

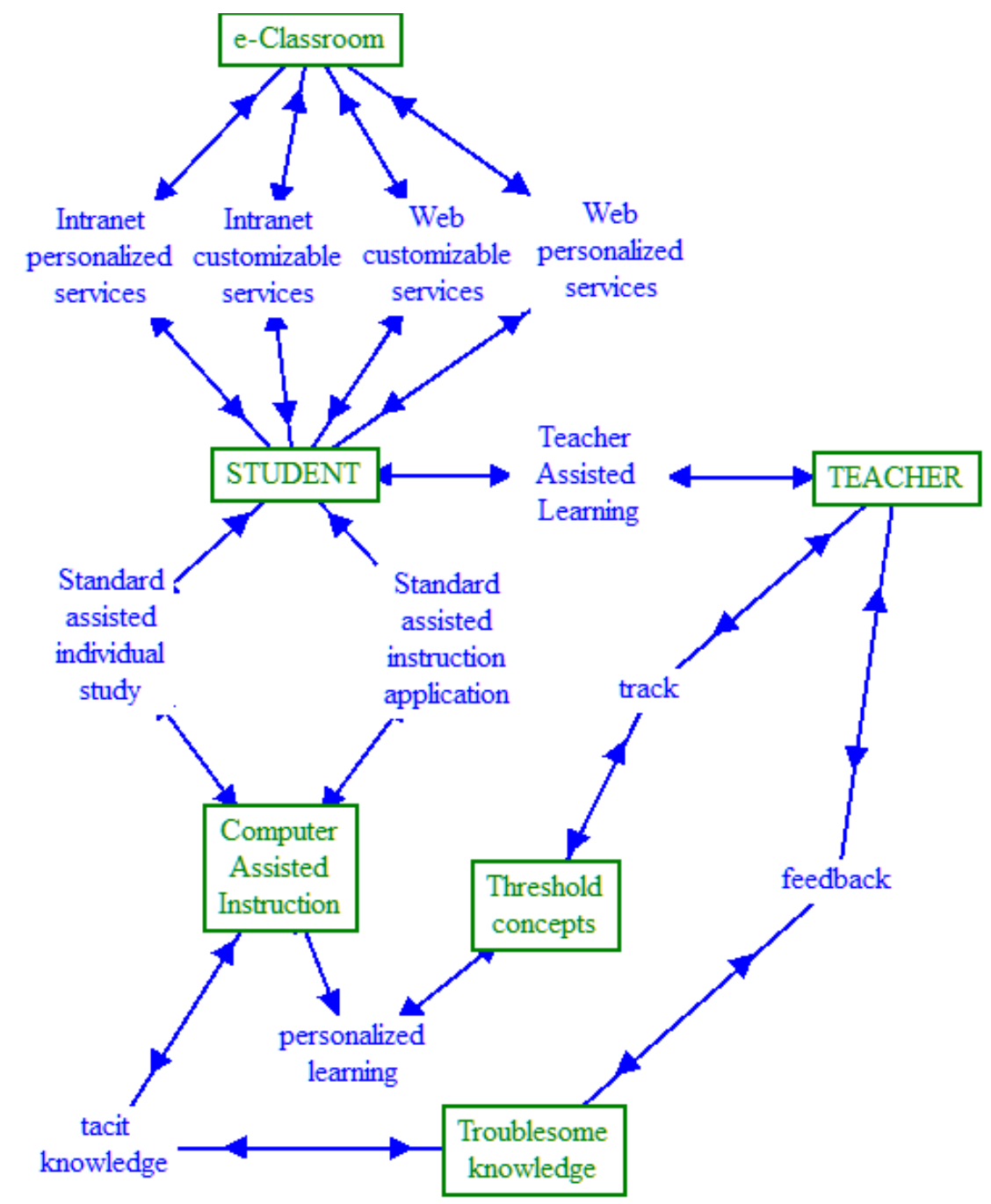

Fig. 4. Standard functionalities for an assisted instruction system in e-Classroom 
This structure highlights two key elements of a face-to-face teaching-learning system in eClassroom, referring to personalized learning and tacit knowledge as two basic components of the student's cognitive system. The personal computers support them as tool, tutor, and tutee. The teachers explain the context and sustain upgrade as new versions for standard assisted individual studies and standard assisted instruction applications, related to improved tutoring options.

\section{Case Study}

Among the attributes that make computers unique is the self-paced characteristic that computers provide. As it is mentioned in [15], students can truly progress at their own speeds - a feat that even the most accomplished human teacher has great difficulty achieving under prevailing conditions. Also, students are given immediate feedback regarding their performance so they can move on the next set of activities without undue delay.

According to [17], in the large class, it is important that rules of conduct, policies, routines, and procedures be set up and followed in a fairly predictable manner. It is important that students know how and when they will be evaluated, what the attendance policy of the class is, how homework is checked, what the syllabus of the course is, how they are supposed to conduct themselves, and what level of achievement is expected from them. Wellestablished routines give students a sense of stability and security. Once such routines are functioning properly, instructions not need to be repeated as often, student responsibility increases and the entire process of teaching and learning work more smoothly.

In e-education, in a standard e-classroom, in a just in time teaching and learning system, all these mentions are by default understandable, and the students have to be focused on threshold concepts and troublesome knowledge of the object language. Every student's activity is a kind of attendance policy and evaluation, and the homework as a self-control of learning through self-assessment.
In a large class, it is significant to create a climate where students will fell safe; in a standard $e$-Classroom, this is a by default feature. In a traditional classroom, the same author [17] mentions that the students will perceive other students as partners in the process of learning, rather than competitors on the success scale. In a standard e-Classroom, the learning process become an efficient one when the students perceive other students as competitors. Students as partners reflects another transversal competence, working in groups for didactic reasons or working in teams, which presumes students as professionals.

In this context, we define an educational laboratory, including fifty personal computers for students and one personal computer for the teacher, all of them connected to internet, with intranet personalized network services and intranet customizable email services.

Setting-up the class calendar for each student's weekly activity, the teaching-learning system activities for a specified discipline are defined. All the students start the same activities (even if the students could be considered advances, intermediate or beginners), so each student progresses at his own speed. Each student asks for clarifying the context or the content. Each student stops in a specific moment and continues next time, from the same specific moment.

In an assisted instruction system, two classes of interactive activities were mentioned before: the standard assisted individual studies and the standard assisted instruction applications.

Here is presented a standard assisted individual study, example to be used in a just in time teaching and learning system, in the standard e-classroom.

Consider a discipline of your study program presenting interest for you as a professional, formulate a theme you had been thinking before, and enumerate five keywords, considered by you as basic concepts for a new documentation activity.

In order to start a web search, you can use a search engine like Bing 


(https://www.bing.com/),
(htps://www.google.com/),
(https://www.yahoo.com/), or you can select
another one, from the web page
http://www.iac.ase.ro/digital_arti-
cle/search.html.

Finally, present five articles, considering representative and useful (with details), for your searches, mentioning for each of them, the author, the title, the online journal, the year of publication, the volume, the ISSN (https://www.issn.org/understanding-theissn/what-is-an-issn/), E-ISSN, or DOI (https://library.uic.edu/help/article/1966/what-is-a-doi-and-how-do-i-usethem-in-citations), and the web address of each of the articles.

In order to solve these requirements, you have to start from the general structure of an article, consisting of: the title, the author, the abstract, the keywords, the article sections, the conclusions, and the references.

Depending on your keywords, and on your settings for you search engine, the list of the results could be different, including, anyway, too many references, to read all of them.

In this context, we decide to read an article from the list as soon as:

- the keywords of the article correspond to our research;

- the abstract and the conclusions correspond to our motivations and objectives;

- the references include the author of the article (it is not a first approach of the author in the subject) and correspond to authors with contributions in the subject or publications with dedicated sections for the domain.

In this moment we can decide if we read the introduction and all the sections, and if we read the content, we can appreciate that the title correspond to the article.

This is a way you have to train to develop your competency for selecting references, and this is an iterative exercise for such an objective, including two parameters: the keywords and the search-engine.

Another stage of your search depends on used keywords as aggregate concepts and then as threshold concepts.

A standard assisted instruction application is based on the threefold function of the personal computer: tool (as a descriptive solution of the problem), tutor (as an explanatory solution of the same problem), and tutee (confirming the learner's activity, regarding the method applied). As it was argued in [14], such an application has to be continued with a dual application. The user has to apply the same method (understood in the primary application) in order to solve a new exercise situated in the same class of problems.

The interface of the application includes an option Reset all, just in case the user alters the content, and an option Reset Square to restore the square (just in case). In order to create a better understanding, there are options in order to solve each step of the problem and corresponding options in order to undo these actions.

The dual application reviews the main steps of the method to sustain the user activities.

Developed as a digital-article, this paper proposes a standard assisted instruction application including a dual-application, which is available in two versions (an English version and a Romanian version) at the web address http://www.iac.ase.ro/digital_article/.

In such an assisted instruction system, after each activity, each student updates his personal web page of the e-classroom, with the files of the theme, and finally, the web page reflects the history of all activities, as a selfcontrol of learning through self-assessment. His email address is also developed and structured as a digital library, consisting off the content he already browsed.

\section{Conclusions}

Developing and experimenting an assisted instruction system in e-education presume JustIn-Time Teaching and Learning activities as knowledge, comprehension, and applications (using assisted instruction applications), then analysis, synthesis, and evaluation (using assisted instruction studies), according to Bloom' s taxonomy of educational objectives. Optimising such an instruction process depends on two basic methodological factors: the first one is the support for a descriptive approach, and the second one is the sustenance 
of an explanatory approach, both of them, integrated in electronic, digital, or virtual resources. In such an environment, the teacher assures the most relevant functionalities of the standard assisted instruction system, as he is responsible for optimising personalized learning and tacit knowledge of the students. At the same time, the teacher develops the support and functionalities of the standard assisted individual study and of the standard assisted instruction applications as new versions, based on the track and on the feedback obtained in the standard e-classroom. The context described, as a general solution, reflects a framework for the recursive process in forming professionals and for the iterative process in developing new versions for $e$-Classroom.

\section{References}

[1] G. Zamfir - Learning Paradigms in e-Society, Informatica Economica, Volume 17, No. 3/2013, pp. 99-113, ISSN 14531305, EISSN 1842-8088, https://doi.org/10.12948/issn14531305/17 .3.2013.09;

[2] T. Hoel, J. Mason - Standards for smart education - towards a development framework, Smart Learning Environments, Volume 5, 2018, Springer Open https://www.springeropen.com/, https://doi.org/10.1186/s40561-0180052-3

[3] R. Koper - Conditions for effective smart learning environments, Smart Learning Environments, Volume 1, 2014, Springer Open, http://www.slejournal.com/content $/ 1 / 1 / 5$

[4] Z. Zhu, Yanyan Sun, Peter Riezebos - Introducing the smart education framework: core elements for successful learning in a digital world, International Journal of Smart Technology and Learning, Vol. 1, No. 1, 2016, InderScience Publishers, https://www.inderscience.com/info/inarticle.php?artid=78159

[5] R. Kumar, N. Pande - Technology-mediated learning paradigm and the blended learning ecosystem: what works for working professionals? Information Technology and Quantitative Management (ITQM
2017), ISSN: 1877-0509, Published by Elsevier B.V., https://www.sciencedirect.com/science/article/pii/S1877050917327369

[6] G. Zamfir - Quality-Quantity Paradigm in Assisted Instruction, Journal of Applied Quantitative Methods, ISSN 1842-4562, Volume 5, Issue 4, December 30, 2010, http://www.jaqm.ro/volume-5,issue4.php;

[7] G. Zamfir - Theoretical and Factual Meaning in Assisted Instruction, Informatica Economică, Vol. 15 No. 2/2011, ISSN: $1453-1305$, p. 94-106, http://revistaie.ase.ro/content/58/09\%20\%20Zamfir.pdf

[8] D. Teodorescu - Introduction in microelectronics, FACLA Publishing House, 1985

[9] G. Zamfir - Assisted Learning Systems in e-Education, Informatica Economica, Volume 18, No. 3/2014, pp. 91-102, ISSN: 1453-1305, EISSN: 1842-8088, https://doi.org/10.12948/issn14531305/18 .3.2014.08;

[10] *** - Innovating Pedagogy 2019, The Open University Innovation Report, ISBN: 9781473028333, available at: https://iet.open.ac.uk/file/innovating-pedagogy-2019.pdf

[11] G. Zamfir - Learning Support for Standard e-Classroom, Informatica Economica, Volume 19, No. 3/2015, pp. 46-58, ISSN: 1453-1305, EISSN: 1842-8088, https://doi.org/10.12948/issn14531305/19 .3.2015.04;

[12] UNESCO - The Right to Education, Law and Policy Review Guidelines, Published in 2014 by the United Nations Educational, Scientific and Cultural Organization, ED-2014/WS/18, available at https://unesdoc.unesco.org/ark:/48223/pf 0000228491

[13] *** - The Law No. 1 of 5 January 2011 - Law on education -, published in the Official Journal of Romania, Part I, No. 18 of 10 January 2011

[14] G. Zamfir - Dual applications for metacognitive development in assisted instruction, Informatica Economica, Volume 21, 
No. 2/2017, pp. 54-67, ISSN: 1453-1305, EISSN: 1842-8088, https://doi.org/10.12948/issn14531305/21 .2.2017.05;

[15] R. V. Bullough, SR., Lamond F. Beatty Classroom Applications of Microcomputers, Columbus: Merrill Publishing Company, 1987, ISBN: 0-675-20525-5, pp. 342.

[16] H. Guo - Application of a Computer-Assisted Instruction System Based on Constructivism, iJET International Journal of Emerging Technologies in Learning, Vol. 13, No. 4, 2018, https://online-journals.org/index.php/i-jet/article/view/8468

[17] N. Hess - Teaching Large Multilevel Classes, Cambridge Handbooks for Language Teachers, Series Editor Penny Ur,
Cambridge University Press, 2001, ISBN: 052166785 2, http://www.cambridge.org

[18] H. Douglas Brown - Teaching by Principles, An Interactive Approach to Language Pedagogy, Second Edition, 480 pages, Published by Pearson ESL, 2001, ISBN-10: 0130282839, ISBN-13: 9780130282835, https://octovany.files.wordpress.com/2013/12/ok-teaching-by-principles-h-douglas-brown.pdf

[19] G. Zamfir - Concepts Map Approach in e-Classroom, Informatica Economica, Volume 16, No. 3/2012, pp. 124-135, ISSN: 1453-1305, EISSN: 1842-8088; available at: http://www.revistaie.ase.ro/content/63/11\%20\%20Zamfir.pdf

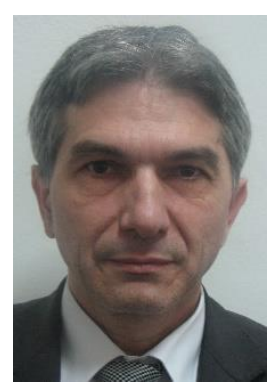

Gabriel ZAMFIR has graduated the Faculty of Planning and Economic Cybernetics from the Academy of Economic Studies Bucharest, in 1984. He worked as analyst for six years and as a researcher for three years at the Research Institute for Computers. In 1993, he joined the staff of the Bucharest University of Economics. In 2000, he finalized the doctoral thesis Computer Assisted Instruction in Economics. Currently he is professor at the Department of Economic Informatics and Cybernetics, involved in research and applications design for e-education. 